\title{
SECOND ORDER DESCRIPTIONS AND GENERAL TERM RIGIDITY
}

\author{
EZEQUIEL ZERBUDIS \\ Universidad de Buenos Aires \\ Universidad Nacional del Litoral \\ ezerbu@yahoo.com
}

\begin{abstract}
SUMMARY: I examine Nathan Salmon's solution to the problem of trivialization, as it arises for conceptions of general term rigidity that construe it as identity of designation across possible worlds. I argue that he does not succeed in showing that some alleged general terms, such as "the colour of the sky" are non-rigid, but also that a small class of different examples that he presents, which can be construed as second order descriptions, are indeed non-rigid general terms, although for reasons different from those he thought.
\end{abstract}

KEY WORDS: semantics, designation, predicative expression, logical form, modality

RESUMEN: Examino aquí la solución propuesta por Nathan Salmon al problema de la trivialización que, según suele suponerse, aqueja a las concepciones de la rigidez para términos generales entendida como identidad de designación en los distintos mundos posibles. Sostengo que este autor no logra mostrar que algunos supuestos términos generales, tales como "the colour of the sky", son no rígidos, pero también que una pequeña clase de ejemplos distintos que él ofrece, que se pueden entender como descripciones de segundo orden, sí resultan ser términos generales no rígidos, aunque por razones distintas que las que él supone.

PALABRAS CLAVE: semántica, designación, expresión predicativa, forma lógica, modalidad

\section{Introduction}

In the present paper, I examine Nathan Salmon's solution to the problem of trivialization, as it arises for conceptions of general term rigidity that construe it as identity of designation across possible worlds; and, in the process of doing so, I will also address some more general issues pertaining to the nature and semantic role of predicative expressions, something that is required if our discussion is to be based on sound ground. Before taking up these topics, anyway, let me first introduce some background considerations that will be useful for understanding what the problem Salmon tries to solve consists in, and the significance of his proposal.

As is well known, the two theses that some singular terms, paradigmatically names, are rigid designators, and that some predicative expressions, particularly natural kind ones, could also be taken as rigid, originate in Kripke's introduction of the notion of rigidity in 
Naming and Necessity (Kripke 1980). But, although the meaning of the first of these two theses has usually been taken to be relatively clear and straightforward, and its truth has almost universally been taken for granted, the second thesis, the one about natural kind terms, is more problematic because it is not very clear what its precise meaning could be: in effect, it is uncertain whether the notion of rigidity applies to predicative expressions in the first place and, if so, how it should be understood. ${ }^{1}$ There is a problem here because, on the one hand, what Kripke defines is not just "rigidity" alone, but "rigid designator", thereby implying that being a designator is a necessary condition for being rigid; but, on the other hand, it is not clear to what extent, and in what sense, predicative expressions could be taken to designate anything.

One can find in the literature on this issue at least two prima facie equally plausible proposals about how to understand predicate rigidity (and, in connection with it, predicate designation): on the one hand, there is a group of proposals that could be described as sameness of designation views, according to which a predicative expression is rigid if and only if it designates the same appropriate entity (a property or a kind) in every possible world, and it is non-rigid otherwise (this is the group to which Salmon's proposal belongs) ${ }^{2}$ on the other hand, there is another group of proposals, the so called essentialist views, according to which a predicative expression will be considered rigid if and only if it behaves as if it expressed a property that is essential to anything that instantiates it, namely, if and only if, if the expression applies to (or designates) a particular object in

${ }^{1}$ I understand by "predicative expression" any kind of expression whose main function consists in ascribing a property (or relation) to one (or more) objects; as such, and contrary to Salmon's usage, I construe the class of such expressions as including not only complete predicates but also the (ordinary language) general terms from which predicates may be formed (I discuss further this notion, and others in the vicinity, in section 2 below). Moreover, I am taking for granted in this paper that natural kind terms are to be taken as predicative expressions. Even though this view has sometimes been contested, I presume I can be allowed to do so in the present context, given that Salmon himself takes them to be so (cf. Salmon 2005 , p. 117, where he treats natural kind terms as a particular class of "general terms", and note 1 on the same page, where he says that "A general term [...] is of a logical type that is potentially applicable [...] to any number of individuals", a characteristic I see as definitional of what a predicative expression is).

${ }^{2}$ Sameness of designation views have been defended, among others, by Bernard Linsky (1984), Joseph LaPorte (2000), Genoveva Martí (2004; cf. also Martí and Martínez 2010, 2011), Nathan Salmon (2005), Dan López de Sa (2008b), and Corine Besson (2010). I have criticized some aspects of Martí and Martinez's and Besson's views in Zerbudis (2012). 
some world, it applies to it in every possible world (in which it exists - though some varieties of the notion drop this last constraint). ${ }^{3}$ We see, then, that each of these ways of construing the notion of rigidity takes different semantic relations, among those connecting general terms with non-linguistic items, as the relevant relation of designation with respect to which the notion is to be defined: in the first case, the privileged relation is the one taking place between a term and the property it expresses; in the other case, the privileged relation is that between the term and each of the individuals it is true of.

In any case, it should be noted that the trivialization problem mentioned at the beginning of this paper only raises a serious problem for "sameness of designation" proposals. In effect, it can be very plausibly assumed that the notion of rigidity, as the essentialists understand it, is not trivial, as not all predicates (at least prima facie) seem to stand for properties that are essential to anything that instantiates them (unless, of course, one adhered to the not very Kripkean metaphysical conception that all properties of particulars are essential to them). On the other hand, if the sameness of designation view amounts to the thesis that every predicative expression designates the property which it expresses, then it is plausible to suppose that, for any such expression, it designates that property rigidly: if "is blue" designates being blue, then it would seem that it designates that property with respect to every possible world; but then it is also reasonable to suppose that the same would happen with "is a bachelor", which would rigidly designate being a bachelor, and with the (for some philosophers non-rigid) "is the colour of the sky", which would (rigidly) designate the property of being of the same colour as the sky.

In what follows, I will first examine the considerations presented by Salmon in order to defend his view from the charge of trivialization, and will later try to single out the underlying assumptions that, in my view, explain why his argument doesn't work. The consideration of these deeper assumptions, in particular of what it means for a term to be predicative, will have as a result that, nonetheless, some of Salmon's examples, but only a few of them, are indeed nonrigid. Finally, I will give some reasons why this result might not be,

${ }^{3}$ Essentialist views have been defended by Monte Cook (1980), Michael Devitt (2005) and Mario Gómez-Torrente (2006). I have criticized some aspects of Devitt's proposal in Zerbudis (2009). 
anyway, such good news for the identity of designation theorist as it may at first sight seem to be.

\section{Salmon's Proposal}

As has been the case with other authors defending the sameness of designation view from the charge of trivialization, such as LaPorte, Linsky, López de Sa and Martí and Martinez, Salmon's strategy also consists in trying to show that there are some expressions that are, at the same time, both general terms and non-rigid. I will consider in this section the arguments by means of which he tries to show, in the second section of his 2005, that one example, "the colour of the sky", which it seems we could take as his "official" example, has both of these characteristics.

Salmon's evidence for his view that the expression is a non-rigid general term is based on its behaviour in the first two premises of the following argument (that I will call "Argument (A)"):

(A1) My true love's eyes are the colour of the sky.

(A2) Blue is the colour of the sky.

(A3) My true love's eyes are blue.

According to Salmon, "the colour of the sky" has the value of a general term in (Al) because it occupies there a position completely analogous to the one that "blue" occupies in (A3), which is clearly a general term position (given that "blue" combines there with the "is" of predication to form a predicate, something that our author takes as "criterial' of the distinction between singular and general terms" (2005, p. 123)). On the other hand, he also considers that term to be "manifestly non-rigid" (p. 122). This gets further support, moreover, from the fact that, on the one hand, the (allegedly second order) identity expressed by (A2) is only contingently true (as a result of which at least one of the terms involved in the identity should be non-rigid, "the colour of the sky" being the most obvious candidate); and that, on the other, given that (A3) seems to follow from (A1) and (A2) by Leibniz's Law, it seems reasonable to suppose that the two tokens of "the colour of the sky" appearing there (the one after the "is" of predication in the first premise, the other after the "is" of identity in the second one) are instances of the same type, so that the properties that can be ascribed to that type, given the way in which it appears in one of the premises, can be held to belong to it in all its appearances. 
I'm really not convinced by Salmon's argument. On the one hand, it seems to me that, for Argument (A)'s validity to lend support to his view, it should be formally such that, just as it is, its conclusion should follow from its premises through a straightforward application of Leibniz's Law, or Substitution of Equality. In my view, though, even if argument (A) is indeed valid, in the intuitive sense that it is impossible for its conclusion to be false in case its premises are true, it is not clear that it has the form required for Leibniz's Law to apply to it directly, as Salmon's view requires. For consider the following argument:

(B1) John has the virtue Socrates was most famous for.

(B2) The virtue Socrates was most famous for is wisdom.

(B3) John is wise.

It is clear that (B3) could not be false if (B1) and (B2) are true, and that therefore the argument is valid in the intuitive sense mentioned above; but it does not follow from this, of course, that the argument is formally such as to yield, just as it is, the conclusion through an application of Leibniz's Law: in order to achieve this, a certain connection must be established between "is wise" and "has wisdom" (for instance, following Salmon's suggestion, through a corresponding "meaning postulate" to the effect that anything is wise iff it has wisdom). In any case, what I would like to stress here is that the intuitive validity of the argument, which can be conceded, cannot be seen as lending support to any conclusion as to the formal connections between, and the specific syntactic and logical profiles of, expressions such as "the virtue Socrates was most famous for" and "wise". If this is so in this case, it seems reasonable to suppose that the same might happen, mutatis mutandis, in relation to the occurrences of "the colour of the sky" in Salmon's (A).

On the other hand, and independently of the validity of the argument as a whole, doubts could also be raised concerning the reasons Salmon gives for his particular way of treating "blue" and "the colour of the sky" in each of the sentences making up (A) - in particular, it seems to me that there are strong reasons to reject his view that both terms belong to the same formal category in each of their two appearances in the argument. I would rather like to argue that, while "blue" is clearly a general term in (A3), it is, on the contrary, a singular term in (A2), namely, just a name of the colour, which in that context it simply designates without ascribing it to any object. 
And something similar may be said of "the colour of the sky", for similar reasons.

Before considering the status of these terms in any more detail, it will be convenient to try to get clearer about some notions that will be important in the discussion, namely, those of general term (or of a general term position), of a first or second order term, and of a predicative expression. As regards the first of these notions, we should remark that the issue of whether an expression is a general term, or of whether it occupies a general term position in a sentence, concerns primarily the level of (what we may call) a surface structure analysis of sentences, a level of analysis that should begin by the elucidation of what Delia Graff Fara (2001) has called the "argument structure" of a sentence (namely, the level concerned with sorting out the expressions that occupy argument positions, and those that do not), but that also includes distinguishing structures, and the suitable components to fill such structures, within those main constituents; in the particular case that interests us here, that of general terms, it seems that an expression should count as a general term if it combines with the "is" of predication to form monadic predicates. ${ }^{4}$ On the other hand, being first or second order seems to correspond to a different level of analysis, namely, that of the representation of a sentence's truth conditions in a formal language whose syntactic categories are intended to reflect corresponding ontological categories; so that a referring expression would be first order if it designates an individual, and second order if it designates a property of individuals, and so on (this level of analysis would correspond to that of logical form, on some understanding of "logical form"). ${ }^{5}$ The notion of a predicative expression, finally, is rather more difficult to apprehend because it appears, with equal right, in both levels of analysis distinguished above; there seems to be a core idea in the notion, anyway (as we already hinted at in fn. 1 above), namely, that what makes a term predicative is that it is used not just to designate an item, but, characteristically, to ascribe it (potentially) to a plurality of other items (of

\footnotetext{
${ }^{4}$ The notion of surface structure used here differs from Salmon's notion of "syntactic form". According to him, "Henry's favourite shirt is blue" and "Henry's favourite colour is blue" share syntactic form (cf. 2005, pp. 130-131); but they don't share surface structure in our use of this phrase. It would take us too far to try to ascertain the relative merits of these two ways of analysing sentences, and I shall not attempt to do that here.

${ }^{5}$ As is well known, "logical form" does not have a univocal sense in the literature, and is understood differently in linguistic and philosophical contexts. Zoltan Szabo's (2012) contains an interesting discussion of the different strands, and contrasting theoretical interests, behind the notions that go under that name.
} 
an appropriate kind). As I have just said, this notion may be used in relation to both levels of analysis mentioned above: both some ordinary language expressions, distinguished by their behaviour at surface level, and some expressions of formalized languages, may be described as predicative. But while whole predicates would count as predicative on both levels, things appear different as regards general terms (or their formal counterparts), something that will be relevant in the discussion to follow: while both the predicates of ordinary language, and the general terms from which they are formed, may be characterized as having a predicative nature (both "wise" and "is wise" are such that, by their very nature, they may be ascribed to different particulars, contrasting, at this level, with referential expressions, which are those that occupy argument positions) only "is \{wise\}", among the corresponding expressions in Salmon's formalism, could be so characterised: according to his view, "wise" by itself apparently only designates the property of being wise. ${ }^{6}$

How do these different notions relate to one another? Salmon's view seems to be that there is a structural match between ordinary language expressions, analysed at the level of surface structure, and their formal counterparts, analysed at the level of logical form (at least if the formalization is carried out with enough detail), and that second order referential expressions, just because of being second order, may play in the formalization the role of general terms. ${ }^{7} \mathrm{It}$ seems to me, on the contrary, that ordinary language general terms,

${ }^{6}$ Notice that Salmon does not use as an example "is \{wise\}", but prefers others, such as "is \{blue\}", in relation to which the suggestion that the term within brackets designates a kind or property seems much more plausible. It seems, though, that he should also take that example as acceptable anyway. It also follows from this that, since he is committed to the view that the two appearances of "blue" in (A) are formally of the same type, even though he takes "blue" as an adjective in (A3), and since, arguably, nothing should depend on peculiarities of his preferred example, he should then accept, it seems, the following as a well formed variant of (B2): "The virtue Socrates was most famous for is wise". That this sentence is unacceptable as a rendering of the identity expressed in (B2) is already an indication that something seems to go wrong in Salmon's proposal.

${ }^{7}$ An anonymous referee has expressed some doubts as to whether Salmon does endorse the claim that being second order (that is, designating a (first order) property) is sufficient for being a general term. Even though I was unable to find textual evidence where Salmon explicitly endorses this, much of what he says seems to me to entail such a view. Notice that the most plausible example of a second order expression that might not be a general term would be an expression purporting to refer to a property, such as "the colour blue", "blue" (as used in (A2)) or "the colour of the sky"; but he says explicitly of the last two that they are general terms, even when they appear in argument positions (cf. 2005, p. 124). It is true that Salmon might also think that, for instance, "wisdom" is a singular (first order) designator 
such as "blue" as it appears in (A3), are not referential expressions, that is, they are not expressions whose only semantic task consists in picking out an entity (of whatever kind) as a suitable object of discourse. I am not denying, in saying this, that general terms somehow pick out properties that play a role in an assessment of the expression's semantic contribution; I think that this is so, but I also think that the expression's contribution to a sentence's meaning goes beyond that, as such expressions seem to have what we could call "ascriptive force" by themselves - otherwise the explanation of a certain range of phenomena involving these terms would be rather strained. I shall not attempt to provide here a full defence of this view; but I shall offer, anyway, the following remarks to motivate it. Consider, first, "bare" uses of such terms, as when one exclaims "Disgusting!" when, say, reacting to someone's behaviour; it seems that in these cases we clearly ascribe the property of being disgusting to such behaviour, even without the copula. ${ }^{8}$ On the other hand, we also characterize people and objects by using predicative expressions outside the sentence predicate, as when we say "Poor Pete lost all his money in the races". Moreover, it would be difficult to understand why it would be natural to say that "My true love's blue eyes are blue" is analytic, in the traditional sense according to which the predicate says (at least part of) what the subject term already said about its denotation, if the first "blue" weren't already ascribing being blue to my true love's eyes. And, finally, the traditional idea that the "is" of predication does not make a substantial (but just a formal) contribution to a sentence's meaning would be equally difficult to account for. ${ }^{9}$

of a property, in contrast to what happens with "blue". But I take it that such a position, according to which some designators for properties are general terms, while some others are not, would exhibit a striking lack of systematicity.

${ }^{8}$ Of course, one could think that there is an ellipsis here. But, even if we accept that as a possibility, then one should expect, if Salmon's story is right, that the speech act in our example could be taken either as an ascription of the property to something else (an elliptical predicate), or as just a mention of the property (a referential term for the property). It seems to me that such ambiguity is not present in the example.

${ }^{9} \mathrm{I}$ am aware that I'm leaving important issues unaddressed here; in particular, more should be said regarding the relative roles played by copula and general terms in an explanation of the ascriptive nature of complete predicates. All I have argued for here and, I think, all I need to argue for in this context, is that their respective contributions cannot be modelled on the relation between, for instance, verb and accusative object in, for example, "... loves John". 
After these preliminary clarifications, let's go back now to the analysis of the relevant examples.

\section{1. "The Colour of the Sky"}

Let's consider now with some more detail the behaviour of "the colour of the sky" as it appears in the first premise of argument (A). Given that this phrase is, in that context, clearly replaceable by "blue" (and in fact it happens to be replaced by it in (A3)), it has to be taken as occupying a general term position. On the other hand, it is also clearly the case that the phrase has the form of a definite description, that is, of a kind of expression that typically occupies argument positions at surface level, and one that clearly occupies one such position in (A2) - even though, as we shall see below, descriptions arguably act in many cases as predicative expressions. Could these two prima facie contrasting properties of the expression be reconciled? And if so, how? Salmon thinks that these two properties can be squared with one another by taking the description to be second order, that is, to designate an entity of higher type, that is, one that has particulars as instances. It seems to be because of this special nature of the entity designated that the term may occupy a general term position, that is, that it may combine with the copula to form a predicate (and so be "predicative" in some sense), even if it (just) designates an entity: the reason is that those entities are, by their very nature, such as to be (possibly) ascribed to a plurality of instances.

Robert May, in unpublished comments on an earlier version of Salmon's paper (cf. May 2003), has criticized some of these views, arguing in particular against the thesis that "the colour of the sky" is second order, and against Salmon's original idea (withdrawn in the published version) that the term should be understood as adjectival. ${ }^{10}$ He defends instead the theses that "the colour of the sky" is to be taken as a first order description, and as a noun (we may here concentrate only on the discussion of the first thesis, given that Salmon does not dispute now the second point). In my view, May's reasons for the thesis that "the colour of the sky" is first order are convincing, and I hope to make it clear in what follows why I think

\footnotetext{
${ }^{10}$ Salmon disavows his previous use of "adjectival" to characterize the behaviour of such descriptions in his 2005 (p. 130, fn. 21), although he was still characterizing them in that way, admittedly with some hesitation, earlier in the same paper: "... some English definite descriptions [...] function rather as if they were adjectives or, more likely, mass-noun phrases" (2005, p. 122).
} 
so. But I'd like to emphasize first of all that both proposals are illequipped to account for the predicative nature of the term as it is used in some contexts, given that both insist on taking the definite description as a mere mechanism of designation. This can be seen clearly in their formalizations of (A). This is Salmon's formalization:

$(\mathrm{AlS})(x)[$ is-a \{eye of my true love $\}(x) \rightarrow$ is $\left\{(\iota F)\left[i s-a^{2}\right.\right.$ \{colour $\}$ $(F) \&$ is $\{F\}$ (the sky)] $\}(x)]$.

(A2S) blue $={ }^{2}(\iota F)\left[i s-a^{2}\{\operatorname{colour}\}(F) \&\right.$ is $\{F\}$ (the sky) $]$

(A3S) (x) [is-a \{eye of my true love $\}(x) \rightarrow$ is $\{$ blue $\}(x)]$.

And this is May's:

$(\mathrm{A} 1 \mathrm{M})(x)[$ is $\{$ an eye of my true love $\}(x) \rightarrow$ is $\{(\iota y)[i s-a$ color $\}(y)$ $\&$ is $\{y\}($ the sky) $]\}(x)]$.

$(\mathrm{A} 2 \mathrm{M})$ blue $=(\iota y)[i s-a\{\operatorname{colour}\}(y) \&$ is $\{y\}($ the sky) $]$

$(\mathrm{A} 3 \mathrm{M})(x)[$ is $\{$ an eye of my true love $\}(x) \rightarrow$ is $\{$ blue $\}(x)]$.

It seems to me pretty clear that, in both formalizations, the ascriptive force of the predicates, or, in any case, that of the predicates in the consequents of (AlS) and (AlM), is made to depend exclusively on the value of the "is" of predication, given that the descriptive expressions in these examples (i.e., the two different tokens of "the colour of the sky") cannot be understood but as designating a certain property, without being able by themselves to ascribe it to anything (and, in relation to this, it doesn't really matter very much whether the description is formalized as first or second order). If "the colour of the sky" is unable to do such a thing but, even when it is taken as second order, merely designates some property, then the alleged "is" of predication has to be understood, pace Salmon, as designating some kind of instantiation relation. This, I take it, is exactly the import of May's criticism that Salmon's "is" is indeed no different from the "is" of possession he had criticised in Soames (May 2003, pp. 10-11; cf. Salmon 2005, pp. 125-126):

We should observe at this point that it is not altogether clear that N[athan] S[almon] does not himself assume a "be" of possession. For consider again his analysis of "be" in terms of metaphysical extension, where the latter notion is defined as the class of possible objects that have some property. Aren't we just bringing possession in through the 
back door in the definition of "our old and dear friend, the "is" of predication?"

On the other hand, and quite independently of this, some of the reasons both authors adduce in favour of their readings seem flawed. May, for example, makes use of Fara's view (2001), which elaborates on ideas already defended by Strawson (1950), according to which some definite descriptions should not be taken as occupying argument positions, but rather as having predicative import. He mentions as evidence in favour of this idea examples such as (C):

(C) Max is the man for the job.

I tend to agree that "the man for the job" is used predicatively in this example. But this fact, if it is a fact, has no direct implication concerning the status of "the colour of the sky" in (A1), since the two cases exhibit a significant difference, namely, that, while "the man for the job" does indeed describe Max in the same sense in which "happy" would describe him if we said "Max is happy" (that is, in the sense that its descriptive content is true of him) "the colour of the sky" does not describe my true love's eyes in that same sense, because, for instance, "colour" is not true of the eyes (as "man" is true of Max). This circumstance is probably behind Salmon's commitment to taking such description as second order, a commitment that, as we noted, is anyway insufficient to account for the predicative force of natural language general terms.

It seems to me that the way out of the dilemma posed by the prima facie contradictory properties apparently exhibited by "the colour of the sky" (namely, occupying a position requiring a (predicative) general term, but being a (usually referential) singular term itself), consists in taking that term, in the context of (A1), as having rather the force of a prepositional phrase such as "of the colour of the sky" - which, by the way, can in fact be substituted for it. ${ }^{11}$

Some evidence in favour of this solution comes from the consideration of parallel arguments in other languages, where the use of prepositions in similar contexts is mandatory. As far as I know, this is so both in French and German, but I prefer to exemplify by using my native Spanish, where (Al) can be rendered in the following way:

${ }^{11}$ Thanks to David Liggins for sharing his intuitions as a native speaker of English. Cf. also "of the colour Angela prefers", an example of an (allegedly) nonrigid general term discussed by Linsky in a similar context (1984, p. 267; the example had been first discussed by David Armstrong, cf. his 1978, p. 57). 
(A1Sp) Los ojos de mi verdadero amor son del color del cielo.

(A2Sp) El azul es el color del cielo.

(A3Sp) Los ojos de mi verdadero amor son azules.

Here, what occupies in (A1Sp) the same position that "azules" (i.e., blue) occupies in (A3Sp) is the phrase "del color del cielo" (i.e., of the colour of the sky), which is not a definite description but a prepositional phrase with adjectival import. And, as we have seen, the preposition, though not mandatory, could also be added in English in this case, and is even mandatory in some other similar cases, including cases in which colours are attributed to eyes, such as (D):

(D) Her eyes were of a very beautiful colour.

I think this evidence strongly suggests, then, that "the colour of the sky" in (Al) has the force of, and is perhaps even elliptical for, "of the colour of the sky".

On the other hand, it seems that "the colour of the sky" is, in general, a singular term. It seems plausible to suppose that, if Salmon holds that the description is indeed second order in (A2), he should be committed to holding the same for all appearances of the term. But the term doesn't seem to behave in the expected way, at least in many cases. Consider, for instance, the following example (E) - similar to some examples presented by May in a different context:

(E) Two of my favourite things are Paula's face and the colour of the sky.

"Paula's face", on the one hand, is clearly a singular term, and it is probably so also according to Salmon's criteria - indeed, it seems absurd to suppose that it could function predicatively, combining with the "is" of predication. On the other hand, it seems plausible to assume that "and" and similar connectives, unite, as a rule, terms that belong to the same grammatical (i.e., surface-structure) and logical categories; this can be shown by considering examples (F) and $(\mathrm{G})$ below: in particular, we see that while $(\mathrm{F})$, which includes two uncontroversial singular terms, is perfectly acceptable, (G) is unacceptable (and, indeed, ungrammatical).

(F) Two of my favourite things are Paula's face and my car. 
*(G) Two of my favourite things are Paula's face and happy. ${ }^{12}$

We can see that $(\mathrm{E})$, our primary example, follows the pattern of $(\mathrm{F})$, not that of $(\mathrm{G})$. If this is so, then it seems to follow that "and" unites two singular terms in (E), and that therefore "the colour of the sky" has to be understood, at least when it appears in argument position, as a singular term.

\section{2. "Blue"}

What about "blue" as it appears in argument (A)? Given that this term appears in this inference in positions strictly parallel to those in which "the colour of the sky" appears, it is to be expected that, just as is the case with this term, "blue" is used as a singular term in (A2) and as a general term in (A3). Indeed, if the two cases are really parallel, what we said so far concerning "the colour of the sky" should be enough to show that their positions require being occupied by a singular term in the one case, and by a general term in the other, which, again, gives us good reason to think that the terms occupying them are indeed as required (given that those two sentences seem perfectly acceptable). This seems to me to be correct, but $\mathrm{I}$ also think that there is further evidence that confirms our thesis that, while "blue" functions in one case as a (singular) name for the colour, it works as a general term (as an adjective) in the other case.

One such piece of evidence comes from considering again argument (B), already mentioned:

(B1) John has the virtue Socrates was most famous for.

(B2) Wisdom is the virtue Socrates was most famous for.

(B3) John is wise.

First of all, if we compare this argument with argument (A), it seems reasonable to assume that (A2) and (A3) are semantically and formally parallel to (B2) and (B3). Moreover, it should also be clear that the two positions occupied by "blue" in argument (A) are occupied by two different terms in argument (B), namely, "wisdom" and "wise", the first of which is an unambiguous name of a virtue

\footnotetext{
${ }^{12}$ This example might seem a little suspicious, given that it includes an adjective ("happy"). Nonetheless, it should be remembered that Salmon treats first order adjectives as second order referential expressions: "How can a definite description combine with the 'is' of predication while designating something? In the same way as the adjective 'blue' or the mass noun 'water'" (2005, p. 123, my emphasis).
} 
and the second of which is an unambiguous adjective ascribing that virtue to somebody, neither of which, besides, could be substituted for the other. If this is correct, then it is reasonable to suppose that the two tokens of "blue" that appear in those two different positions in argument (A) are indeed, either two different (homophonic) words, or two different uses of a single word: in one case what we have is a name for the colour, in the other an adjective ascribing that colour to some particulars.

Further evidence for the same conclusion might be obtained, it seems, from a consideration of the argument (ASp), the Spanish version of $(\mathrm{A})$, which we also mentioned above:

(A1Sp) Los ojos de mi verdadero amor son del color del cielo.

(A2Sp) El azul es el color del cielo.

(A3Sp) Los ojos de mi verdadero amor son azules.

Here "el azul" in (A2Sp) corresponds to "blue" in (A2), while "azules" in (A3Sp) corresponds to "blue" in (A3). The differences we find in the corresponding terms in Spanish, I submit, make it plausible to think of "blue" as having two radically different uses, or as being indeed two different words, as it appears in argument (A) (as a name for the colour in one case, as an adjective ascribing it in the other). This seems to be so because, contrary to what happens in some languages, such as English, adjectives in Spanish (and other languages) take gender and number inflexions, while they can at most take number inflexion when they are used as nouns, and have no inflection at all when they are used as abstract names, as is the case with "azul" in (A2Sp). ${ }^{13}$ On the other hand, the presence of the article "el" also strongly suggests, taking into account some general facts about Spanish usage, that "azul" is used here as a noun, so that both words contribute to make up a singular term used to designate the colour.

If what has been said so far concerning the form and the status of the terms making up argument (A) is correct, then it should be

\footnotetext{
${ }^{13}$ We find no gender inflection in the adjective in our example because "azul", as an adjective, has the same form for both the masculine and the feminine; but we could as well have replaced it by an adjective such as "negro", that does so inflect, and in that case we would have noticed that the term would have changed the ending as a result of a difference in gender in the subject. Compare, for example, "Las cejas de mi verdadero amor son negras" vis à vis "Los ojos de mi verdadero amor son negros".
} 
clear that that argument, notwithstanding its intuitive validity, is not, just as it is, formally valid as an instance of Leibniz's Law. On the other hand, it is also clear that it could be transformed into such a formally valid argument by supplementing it, as Salmon points out, with some "meaning postulates" - for instance, in this case, with one postulate to the effect that everything that is blue (where "blue" is an adjectival general term) instantiates blue (where "blue" is an abstract noun), and a further, similar one, for "the colour of the sky". It does not seem to me that this is as problematic as Salmon seems to think, but I won't try to argue for this view here.

\subsection{How This Relates to the Trivialization Problem}

Now, what follows from the discussion above as regards the main issue of this paper, namely, the trivialization problem for general term rigidity? In my view, it undermines Salmon's particular way of arguing for his solution to the trivialization problem. As we saw, his strategy consists in showing that some terms (for instance, "the colour of the sky") are at the same time general and non-rigid terms. He thinks he has shown that a term such as "the colour of the sky" is a general term because, as he argues, it occupies a general term position in (Al), and he thinks that he has also shown that it is non-rigid because it appears, in (A2), in a contingently true identity statement the other term of which is arguably rigid. Our discussion above, however, showed that the expressions that appear in those two sentences are not indeed tokens of a single term (type). In particular, it follows from what we said that, while the term appearing in (A2), which is in fact non-rigid, is not there a general term, but a singular one, the occurrence of (what prima facie seems to be) the same term in (A1) occupies a general term position not in its own right, but as elliptical for a whole prepositional phrase that includes it. In any case, no compelling reason has been given for the view that that term is able to occupy those two positions as a second order definite description.

Now, since the main reason that Salmon has given in favour of the view that there are terms that are, at the same time, predicative and non-rigid consists in arguing that terms such as "the colour of the sky" are second order definite descriptions, then, in so far as the evidence in favour of such a view is not compelling, there are still no strong enough reasons to think that there are any non-rigid general terms. And, to that extent, there is still no satisfactory answer to the charge of trivialization. 
It is nonetheless true that, even if what we have just said is correct, we would only have shown that Salmon's particular strategy for arguing that there are non-rigid general terms, and in particular that "the colour of the sky" belongs to this class, fails; but, for all that, it could still be the case that this term is non-rigid, even if construed as equivalent to "of the colour of the sky". Are there any more general reasons that could help us decide whether such predicative expressions are rigid or not? In order to answer this question, it is crucial to get clearer on how to analyse phrases such as "of the colour of the sky". ${ }^{14}$ There seem to be two main alternative ways in which one could analyse such expressions, according to whether we take (or not) the description as a singular term occupying an argument position: (a) on the one hand, if we don't see it as occupying such a position, the most reasonable interpretation would be to take "of the colour of the sky" as completely equivalent to an adjective (or adjectival phrase), such as, say, "coloured as the sky" - in the same way as, for instance, "of wealth" is equivalent to "wealthy"; (b) on the other hand, we might see the description as occupying an argument position in such expressions, as it does in, say, "... likes the colour of the sky" (so that "... of ...", or "... is of...", would express a relation, just as "... likes ..." does in this other example). ${ }^{15}$ Even though I tend to favour the first of these readings, I shall not defend that view here, as we do not have to settle this issue in order to reach a conclusion concerning the rigidity of predicative expressions: actually, neither interpretation seems to give much support to the view that there are non-rigid predicative expressions involved in this kind of example. In effect, if we consider construal (a) we see that, if the prepositional phrase is indeed equivalent to a singleword adjective, (as "wealthy" is equivalent to "of wealth"), then it should be taken as rigid, in the same sense, and for the same reasons, for which single-word adjectives are usually taken to be so (I assume that both parties in the discussion agree that this is the case). If, on the other hand, we consider construal (b), then we'll

${ }^{14}$ Unlike Salmon (cf. now also his 2011), and as is probably implicit in my discussion above, I don't think that, as far as designation is concerned, there is much difference between a general term and the predicate built from it, but I cannot elaborate on this point here.

${ }^{15}$ Moreover, the description could be taken, in this second reading, either as (i) attributive or (ii) referential. I don't consider these further alternatives in the main text because the issue is not relevant for an assessment of the rigidity of predicative expressions. But it is interesting to note that, if the description is understood referentially, then the whole predicate would also be rigid. 
have to take the description as lying outside the properly predicative (i.e., general-term like) part of the predicate, just as "the colour of the sky" lies outside the properly predicative part of "... likes the colour of the sky": in this example, "likes" stands for a relation that connects the designata of the singular terms flanking it, and, clearly, it is the only properly predicative expression in the example. ${ }^{16}$ But, on the most natural way of understanding the problem of general term rigidity, it concerns precisely whether predicative expressions, or terms, not complete predicates containing singular expressions, could be non-rigid (indeed, the latter question could have been solved fairly easily: "... loves the president of the US" would be such a non-rigid predicate). I conclude, then, that, if our analysis of this example is correct, we have good reasons to suppose that no properly predicative expression involving "the colour of the sky" is non-rigid.

\section{Salmon's Other Examples and Genuine Second Order Descriptions}

Something similar to what we have found concerning "the colour of the sky" is also to be found, in my view, in most of the other examples of (allegedly) non-rigid predicative expressions presented by Salmon, such as "Henry's favourite beverage" and "the chemical compound composed of two parts hydrogen, one part oxygen". Indeed, it is not clear whether any of these ever appear in genuine predicative positions. For instance, a sentence such as "This is Henry's favourite beverage", uttered, say, in front of a can of beer, is most naturally understood, I think, not as ascribing a property to a particular amount of liquid referred to by "this", but, on the contrary, as asserting the identity between the kind referred to by the indexical (arguably, (a specific kind of) beer) and the kind designated by "Henry's favourite beverage", a phrase which, as "the colour of the sky", is most naturally taken in that context as a singular term. ${ }^{17}$

\footnotetext{
${ }^{16}$ This may be observed not only in verbal predicates, but also in, for example, "sympathetic to my view", which is an adjectival phrase.

${ }^{17}$ Evidence in favour of this view might perhaps also be obtained by considering some parallel examples in more inflected languages. For instance, while in Spanish "This is beer" (with "beer" being used to ascribe the property of being beer to a concrete amount of liquid) becomes "Esto es cerveza", "This is Henry's favourite beverage" becomes "Ésta es la bebida favorita de Enrique"; it seems plausible to suppose that the change from neuter to feminine in the demonstrative accompanies the change from reference to a particular instance of liquid to reference to the corresponding kind (the relevant kinds are, in this case, grammatically feminine:
} 
Be that as it may, it seems that we face a different situation in relation to another of the examples that he discusses, namely, with "what I am" as it appears in $(\mathrm{H}):^{18}$

\section{(H) What I am is nauseous.}

It seems to me that, contrary to what is the case, as we argued, in statements such as (A2) and (B2), this is a genuine second order identity sentence, and, in particular, that "what I am" is, in general but also in this context, a predicative expression. ${ }^{19}$ The reasons for thinking so could be expressed as follows: on the one hand, "nauseous" can only be construed as a general term, that is, as an expression typically used to ascribe properties (instead of being used to refer to them); but, on the other hand, the "is" that appears in (H) could not be understood as the "is" of predication (it does not combine with "nauseous" to form a predicate ascribing the property of being nauseous to the referent of "what I am"), but as the sign of (here: second order, or general term) identity. And, finally, "what I am" also functions typically, and perhaps exclusively, as a predicative expression, as, for example, in (I):

(I) He was what I am (sc. nauseous).

On the other hand, it seems that $(\mathrm{H})$ is only contingently true (or false, as the case may be), given that I might have been something other than nauseous in the circumstances in which $(\mathrm{H})$ was uttered, which by itself is enough to show that at least one of the two terms appearing in the identity is non-rigid; and, moreover, "what I am" seems the obvious candidate to be construed as the non-rigid term - much more so, at any rate, than "nauseous" is.

If things are so, then, it seems that there are after all expressions that could be characterized as second order descriptions and that are, at the same time, both general terms and non-rigid, as a consequence of which the notion of general term rigidity would indeed turn out to be non-trivial. So that, after all, it seems that the materials for a solution to the trivialization problem were already available in Salmon's paper, only that it is a solution slightly different from the

bebidas); of course, more should be said in order to establish this point, but I will not attempt to do so here.

${ }^{18}$ Cf. Salmon 2005, p. 127.

${ }^{19}$ By "second order identity" I mean, in this context in which we are discussing ordinary language expressions, the same as by "identity between general terms". 
one he explicitly endorsed there. It may be urged, however, that even if this different solution can withstand the difficulties raised above for the proposal based on examples such as "the colour of the sky", there might still be some other objections that would be effective against the non-rigid, general term status of "what I am" and similar expressions. In the rest of this section, I consider a couple of such objections; in the end, it seems to me that all of them are faulty, and that the prima facie non-rigid general term character of these expressions could still be maintained after closer scrutiny.

What considerations could be adduced in favour of the view that examples like "what I am" do not after all undermine the general assumption that all predicative expressions are rigid? I can only think of the following three:

(i) A first such consideration would consist in supposing that a sentence like $(\mathrm{H})$ is nothing other than a stylistic variation (or superficial transformation) of a canonical predication such as $(\mathrm{K})$ :

(K) I am nauseous.

Indeed, if this is correct, $(\mathrm{H})$ could then be considered as having the same logical form as (K) (a form which, moreover, one has to assume to be accurately mirrored by the argument structure of $(K))$. On the other hand, given that "nauseous" is the only genuine general term in $(\mathrm{K})$, and that it is an admittedly rigid general term, an example such as $(\mathrm{H})$ would therefore not involve any threat to the idea that all general terms are rigid.

I don't think that this strategy really succeeds. In the first place, notions such as that of (logical) form (or of representational structure) are notoriously dependent on the theoretical function they are expected to play. In this sense, it is clear that, for some purposes, $(\mathrm{H})$ could be considered as having the same form or the same underlying structure that $(\mathrm{K})$ has. But it should now be remembered that the phenomenon we are focusing on is a rather superficial one, that is, one that mainly concerns the surface structure of sentences, and that therefore, for our purposes, the fact that two sentences such as, say, "John is wise" and "John instantiates wisdom" are necessarily equivalent is no evidence that they have the same form in the relevant sense. This has direct application to our cases $(\mathrm{H})$ and $(\mathrm{K})$ : from the fact that they are equivalent, and that "nauseous" appears predicatively in the latter (that is, in a non-argument position), it doesn't follow that it must also appear predicatively in the former; on the contrary, precisely the fact that in the former "nauseous" appears in 
an argument position must be taken as a reason to take $(\mathrm{H})$ to have a different form from (K).

(ii) A second reason that could be given in order to avoid the conclusion that some predicative expressions are non-rigid would consist in supposing that $(\mathrm{H})$ should be construed as really expressing a metalinguistic statement, along the lines of $(\mathrm{L})$ :

(L) "Nauseous" may be used to complete the open formula "I am ..." adequately.

I think that this proposal should be rejected for a number of reasons. First of all, we have the problems pertaining to the relations between logical equivalence and logical form that we already considered in relation to the previous proposal, something which applies here even more strongly because in this case the relevant sentences are not necessarily equivalent. But this proposal faces also a more specific problem, namely, that there simply seems to be no independent reason for accepting the metalinguistic reading as the standard, or even as an acceptable, reading of our sentence $(\mathrm{H})$, over and above the circumstance that such a construal would allow us to keep the thesis that all predicative expressions are rigid. In fact, if (L) were the standard reading of sentences such as $(\mathrm{H})$, one would expect that, if this is due to the fact that $(\mathrm{H})$ is a pseudo-cleft sentence, $(\mathrm{N})$ should then express the standard reading of $(\mathrm{M})$ :

(M) What I bought is a house.

(N) "A house" could be used to complete the open formula "I bought ..." adequately.

But I cannot see any reason why one should believe that these sentences should be understood in this way; clearly, (M) is about some concrete thing that its utterer bought, presumably a house, but it is not about "a house". Moreover, there seems to be no indication in the example that one could take as suggesting a metalinguistic construal, such as explicit mention of expressions or the use of predicates that could only apply to expressions, something which also applies to our initial example $(\mathrm{H})$; it seems to follow, then, that this reading would be as little plausible in the latter case as in the former.

It is important to emphasize, again, that the only reason in favour of this construal seems to be the desire to safeguard the (initially 
intuitive enough) general assumption that only singular terms could occupy argument positions. But given that an example such as "what I am" behaves as a non-rigid general term is expected to behave, and that it can actually occupy what cannot be understood but as second order argument positions, the sensible policy seems to be simply to abandon the general rule as inadequate. Failing this, there is no genuine reason, then, to adopt the metalinguistic proposal.

(iii) A third way in which one could try to resist the conclusion that some predicative expressions are non-rigid would consist in holding that, even though in some contexts, as that exemplified by $(\mathrm{H})$, in which it appears in an argument place, a general term such as "what I am" is indeed non-rigid, terms of that kind will nevertheless always be rigid when they appear in genuine predicative positions, such as in $(\mathrm{O})$ :

(O) He finally became what he had never been before (sc. happy/ a respected person).

The idea would be that "what he had never been before", as it appears in $(\mathrm{O})$, should not be understood as designating, as suggested by the expressions given between brackets, different properties in different circumstances (such as the properties of being happy or of being a respected person), but that, on the contrary, it should be taken as designating, instead, the same property across all possible worlds -in this case, this property rigidly designated would be something like being what $S$ had never been before $t$ (where " $\mathrm{S}$ " and " $t$ " are schematic letters that designate, rigidly, for every particular utterance, the speaker and time of the utterance of a token of the predicative expression in $(\mathrm{O})$ ).

What kind of considerations could help us decide between these two contrasting interpretations? I believe that the issue is of such a nature that it is difficult even to think of giving a conclusive answer. But, in my view, the evidence available suggests that the non-rigid interpretation is the right one.

First of all, it would seem that, in relation to this particular example, we can present a formally valid argument, based on Leibniz's Law, of the kind that Salmon was looking for when he produced argument (A). Argument (P) would be such an argument:

(P1) He was what I am (= (I) above).

(P2) What I am is nauseous $(=(\mathrm{H})$ above $)$. 
(P3) He was nauseous.

It seems to me that we do not find here the problems that we met with when discussing argument (A), and that there seems to be nothing to suggest, as was the case in relation to that argument, that this one is not complete as it is. If things are so, then, one had better conclude that "what I am" is a non-rigid general term in both cases - as the contingent character of (P2) attests.

Moreover, the expressions between parentheses with which (O) ends seem to suggest that expressions of the kind of "what I am" are usually intended as replaceable by some other, more specific ones, which would, so to speak, give the "solutions" to the puzzles implicit in such assertions (which correspond to questions that the speaker anticipates the audience are implicitly asking themselves). That is, it is as though the utterer specifically used, at least in some cases, a deliberately roundabout manner to refer to a definite property he could have referred to in a much more straightforward way - so that, in the case of $(\mathrm{O})$, he should be taken as designating, according to what happens in the different worlds (and different contexts), the properties of being happy, or of being a respected person. And, as I said, it is clear that things are so at least in some cases - and that is all we need here. ${ }^{20}$

\section{Conclusions}

We have examined, then, in the first place, the arguments by means of which Nathan Salmon has tried to show that predicative expressions are not trivially rigid, and we have found them partially unsatisfactory. He argues in favour of the non-trivial character of his preferred notion of rigidity by presenting some examples of (allegedly)

${ }^{20}$ I am not implying that the use of "what I am" discussed in this section is the only one, or even the most common one, that this expression has. Arguably, there are at least two other equally acceptable uses of it from which this one should be distinguished: on the one hand, the expression may be used, not to single out one specific property the relevant individual has, but to refer globally to the whole of its properties, as in (one understanding of) "I'll never know what I am"; in this use an argument such as $(\mathrm{P})$ could still be valid, only that it would be difficult to find a second premise that could be accepted as true. On the other hand, the expression can also be used to express an indirect question, in which use it is not replaceable by a single term, but by a whole proposition, as in "He didn't know what I am", equivalent in some contexts to "He didn't know that I am a philosopher"; when the term is used in this way, substitutions based on identities such as (P2) will not usually be truth preserving. I'd like to thank Gonzalo Rodriguez-Pereyra for pressing me on this point. 
non-rigid general terms, but we have found that the reasons he has given for thinking that many of them, including the paradigmatic "the colour of the sky", are such are unconvincing. On the other hand, we have found that one of his examples, and many similar ones that could be formed in the same way, are indeed, arguably, nonrigid, although for reasons somewhat different from those Salmon gives. So that it would seem that the notion of general term rigidity is not trivial, after all.

Let me finally say a word on the relevance of the preceding discussion for Kripke's thesis that natural kind terms are rigid, and more broadly for the project of using the notion of rigidity to make a significant distinction among general terms. Contrary to most of the authors who argue that there are some non-rigid predicative expressions, I don't think that the notion of rigidity as identity of designation, even if non-trivial, constitutes an adequate extension, applicable to predicative expressions, of the original notion of rigidity that Kripke defined for singular terms. I think so because, on the one hand, it is clear that the kind of expression found to be non-rigid is so marginal among general terms, and involves descriptive resources of so limited a nature, that it could hardly play the role of an adequate foil to Kripke's rigid natural kind terms; and, on the other hand, but relatedly, because being non-trivial is only a first, necessary condition, for any notion of predicate rigidity to count as an adequate extension of the singular term notion and, it seems to me, the sameness of designation view fails to satisfy some other important desiderata - mainly, that natural kind terms should be, if not the only rigid terms, at least paradigmatically such in ways in which other terms are not; and that rigidity should validate the necessitations of true identification sentences, which I assume should be construed as universally quantified biconditionals (cf. Soames 2002, p. 263, for a statement of similar desiderata). It seems to me, indeed, that there is really no adequate extension of the notion of rigidity to general terms if the notion is to do most of the theoretical work it did in the case of singular terms. But it lies outside the scope of the present paper to try to argue in favour of these theses in any more detail. ${ }^{21}$

${ }^{21}$ I would like to thank Berit Brogaard, Maite Ezcurdia, Eleonora Orlando, Gonzalo Rodriguez-Pereyra, Benjamin Schnieder and anonymous referees for comments on earlier versions of this paper. 


\section{REFERENCES}

Armstrong, David, 1978, A Theory of Universals (Universals and Scientific Realism, Volume II), Cambridge University Press, Cambridge.

Beebee, Helen and Nigel Sabbarton-Leary (eds.), 2010, The Semantics and Metaphysics of Natural Kinds, Routledge, London.

Besson, Corine, 2010, "Rigidity, Natural Kind Terms, and Metasemantics", in Beebee and Sabbarton-Leary 2010, pp. 25-45.

Cook, Monte, 1980, "If 'Cat' is a Rigid Designator, What Does it Designate?", Philosophical Studies, vol. 37, no. 1, pp. 61-64.

Devitt, Michael, 2005, "Rigid Application", Philosophical Studies, vol. 125, no. 2, pp. 139-165.

Fara, Delia Graff, 2001, "Descriptions as Predicates", Philosophical Studies, vol. 102, no. 1, pp. 1-42 (originally published with the name "Delia Graff").

Gómez-Torrente, Mario, 2006, "Rigidity and Essentiality", Mind, vol. 115, no. 2, pp. 227-259.

Kripke, Saul, 1980, Naming and Necessity, Harvard University Press, Cambridge, Mass.

LaPorte, Joseph, 2000, "Rigidity and Kind", Philosophical Studies, vol. 97, no. 3, pp. 293-316.

Linsky, Bernard, 1984, "General Terms as Designators", Pacific Philosophical Quarterly vol. 65, pp. 259-276.

López de Sa, Dan, 2008a, "Rigidity for Predicates and the Trivialization Problem", Philosophers' Imprint, vol. 8, no. 1, pp. 1-13.

—_ 2008b, "The Over-Generalization Problem: Predicates Rigidly Signifying the "Unnatural"', Synthese, vol. 163, no. 2, pp. 263-272.

Martí, Genoveva, 2004, "Rigidity and General Terms", Proceedings of the Aristotelian Society, vol. 104, no. 1, pp. 129-146.

Martí, Genoveva and José Martínez, 2011, "General Terms, Rigidity and the Trivialization Problem", Synthese, vol. 181, no. 2, pp. 277-293.

— 2010, "General Terms as Designators", in Beebee and SabbartonLeary 2010, pp. 46-63.

May, Robert, 2003, "Comments on Nathan Salmon "Are General Terms Rigid?"', Princeton Semantics Workshop, available at: <http://kleene. ss.uci.edu/ rmay/Salmon.pdf > [last accessed: 22 May 2012].

Salmon, Nathan, 2011, "Generality", Philosophical Studies, available as: DOI 10.1007/s11098-011-9772-8.

— 2005, “Are General Terms Rigid?”, Linguistics and Philosophy, vol. 28, no. 1, pp. 117-134.

Soames, Scott, 2002, Beyond Rigidity. The Unfinished Semantic Agenda of Naming and Necessity, Oxford University Press, Oxford.

Strawson, Peter, 1950, "On Referring", Mind, vol. 59, no. 235, pp. 320 344. 
Szabó, Zoltán Gendler, 2012, “Against Logical Form”, in G. Preyer (ed.), Donald Davidson on Truth, Meaning, and the Mental, Oxford University Press, Oxford.

Zerbudis, Ezequiel, 2012, "Natural Kinds, Natural Kind Terms, and the Notion of Rigidity", Teorema, vol. 31, no. 2, pp. 171-185.

_ 2009, "The Problem of Extensional Adequacy for Devitt's Rigid Appliers", Análisis Filosófico, vol. 29, pp. 219-237.

Received: November 29, 2012; revised: March 20, 2013; accepted: September 30, 2013. 